\title{
Comfortable suture angle with optimized trocar position aids renorrhaphy during retroperitoneal laparoscopic partial nephrectomy
}

\author{
Jian Qian', Qian Zhang', Qiang Cao', Jie Jiang', Pu Li ${ }^{1}$, Meiling Bao ${ }^{2}$, Chao Qin ${ }^{1}$, Zengjun Wang ${ }^{1}$, \\ Lixin Hua ${ }^{1}$, Pengfei Shao ${ }^{1}$ \\ ${ }^{1}$ Department of Urology, First Affiliated Hospital with Nanjing Medical University, Nanjing, China; ${ }^{2}$ Department of Pathology, First Affiliated \\ Hospital with Nanjing Medical University, Nanjing, China \\ Contributions: (I) Conception and design: P Shao, L Hua; (II) Administrative support: P Shao, Z Wang; (III) Provision of study materials or patients: \\ P Shao, C Qin, L Hua; (IV) Collection and assembly of data: J Qian, Q Zhang, J Jiang, P Li, M Bao; (V) Data analysis and interpretation: J Qian, Q \\ Zhang, Q Cao; (VI) Manuscript writing: All authors; (VII) Final approval of manuscript: All authors. \\ Correspondence to: Pengfei Shao, MD, PhD; Lixin Hua, MD, PhD. Department of Urology, First Affiliated Hospital with Nanjing Medical University, \\ Nanjing, 300 Guangzhou Road, Nanjing 210029, China. Email: spf032@hotmail.com; lixinhua@njmu.edu.cn.
}

Background: This study investigated a comfortable suture angle (CSA) with optimized trocar position for closing the defect during renorrhaphy in retroperitoneal laparoscopic partial nephrectomy (LPN). The feasibility, usefulness, and safety of achieving the CSA with modified trocar position were determined for different tumor types.

Methods: Two optimized trocar positions were introduced for different tumor types. A suture angle was based on the tumor plane of the superficial parenchyma defect and the line formed by the needle holder. Preliminary surgical simulations determined a CSA that combined the least suture time with the greatest ease of performance. Achieving the CSA was attempted during renorrhaphy of 106 enrolled patients undergoing retroperitoneal LPN. Patients' characteristics, operative features, and follow-up information were collected and analyzed.

Results: For 89 (83.96\%) patients, a CSA was successfully reached and parenchyma recovered. The remaining 17 patients were successfully sutured, but the attempt to achieve a CSA failed. For the CSA group, the suture, clamping, and overall operative times were significantly less than that of the non-CSA patients. The groups were similar regarding estimated blood loss, positive surgical margin, and rates of glomerular filtration reduction and complications. Univariable analyses determined that tumor location, growth pattern, and R.E.N.A.L. nephrometry score (RNS) may influence the success of this approach. Multivariable analyses indicated that only tumor location and RNS were independent factors affecting successful achievement of the CSA.

Conclusions: Through different kidney position changes, the CSA could be used to ease the suture process. It is feasible and safe to perform a CSA with optimized trocar position during LPN. Tumor location and RNS may influence the approach to get a CSA.

Keywords: Renal cell carcinoma; suturing; laparoscopic partial nephrectomy (LPN); renorrhaphy; suture angle

Submitted Jul 28, 2020. Accepted for publication Dec 29, 2020.

doi: $10.21037 /$ tau-20-1126

View this article at: http://dx.doi.org/10.21037/tau-20-1126 


\section{Introduction}

Partial nephrectomy is now introduced to treat clinical T1 kidney tumors when indicated (1). The trifecta aim of partial nephrectomy is to completely excise the tumor with negative margins, with maximal functional preservation, and complication-free recovery (2). Partial nephrectomy has mainly focused on long-term control of bleeding and avoidance of urinary leakage. However, as suture techniques have improved, renorrhaphy has become important for preserving intraoperative vascularized parenchyma and subsequent renal function (3). Indeed, renorrhaphy is a key procedure during partial nephrectomy to recover parenchyma defect.

In laparoscopic partial nephrectomy (LPN) the introduction and adoption of new techniques has greatly enhanced suturing procedures. Advanced techniques include the sliding-clip (4), single or double-layer (5), Vhilar (6), ring (7), and barbed. These novel techniques and maturity of surgical skills have shortened warm ischemic time to preserve more normal parenchyma, and improved renal function recovery.

Especially, the advent of surgical robots has brought laparoscopic suture technology into a new era. However, the expense of robotic surgery has limited its application in less advanced regions, while LPN is still widely used in many countries.

A classical approach in LPN has been the retroperitoneal, which differs in surgical skills from the transperitoneal. While many new suture methods have been reported, articles have emphasized technology, without systematic descriptions of the surgical processes. Thus, explications of approaches, port distribution, and methods to achieve easy suturing are required.

Herein we introduce the novel concept of comfortable suture angle (CSA), to ensure the least suture time with the greatest ease of performance with optimized trocar position. The study investigated approaches to achieve the CSA, and assessed the feasibility and safety of CSA for renorrhaphy during LPN.

We present the following article in accordance with the MDAR reporting checklist (available at http://dx.doi. org/10.21037/tau-20-1126).

\section{Methods}

\section{Patients and perioperative examination}

A prospective study was conducted from June 2017 to
November 2018 with 106 patients who underwent LPN, with either precise segmental artery clamping or main renal artery clamping. All the patients had received a diagnosis of clinical T1 renal tumor $(\leq 7 \mathrm{~cm}$ in diameter) and had normal contralateral renal function. Patients with atrophic or solitary kidney were excluded in this study. All the surgeries were performed by three surgeons (Dr. P Shao, Dr. L Hua and Dr. Z Wang) and each had experience of more than 300 LPN cases. The study was conducted in accordance with the Declaration of Helsinki (as revised in 2013). The study was approved by the Local Ethics Committees of First Affiliated Hospital with Nanjing Medical University (NO.: 2016-SRFA-009) and informed consent was taken from all the patients.

All patients received computed tomography and dualsource computed tomographic angiography before the operation, to evaluate the tumor-specific and patientspecific characteristics and establish the renal vasculature model as described in our previous work $(8,9)$.

The split renal function of the patients was evaluated prior to surgery, and 3 months after surgery, using renal scintigraphy with a camera-based Gate's method to measure the renal uptake of technetium-99m diethylenetriamine pentaacetic acid.

\section{Types of tumors}

Based on Didio's (10) and Anderson et al.'s (11) work, as well as the anatomical distribution of the segmental arteries, the classification of the renal segment and kidney were divided into the following four areas: anterior, posterior, lower polar, and upper polar (Figure 1). A tumor $>50 \%$ within the specific part was defined as within that area. Exophytic, mesophytic, and endophytic tumors were considered to extend $>60 \%, 40-60 \%$, and $<40 \%$, respectively, from the natural surface of the kidney (12).

\section{Optimized port distribution and surgical approaches}

Patients were placed in the lateral decubitus position, with four laparoscopic ports placed in the lumbar (Figure 2). The first port (A, $10 \mathrm{~mm}$ ) was placed $2 \mathrm{~cm}$ above the iliac crest for the laparoscope. The retroperitoneal space was established using an insufflated balloon. Ports B (12 $\mathrm{mm}$ for right side or $5 \mathrm{~mm}$ for left side depending on the convenience of operation) and $\mathrm{C}(5 \mathrm{~mm})$ were placed at the anterior abdominal wall for instruments. Port D $(12 \mathrm{~mm})$ was placed below the tip of the twelfth rib. The 

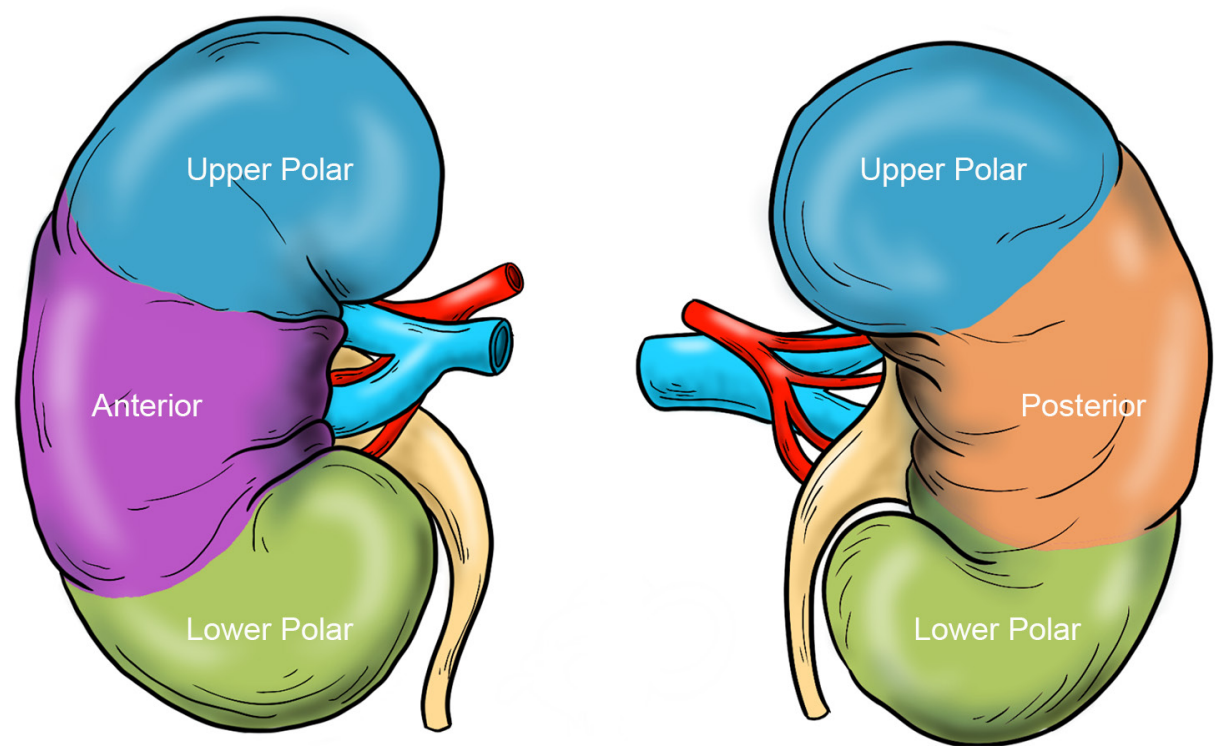

Figure 1 Different tumor locations (anterior, posterior, lower polar, upper polar).
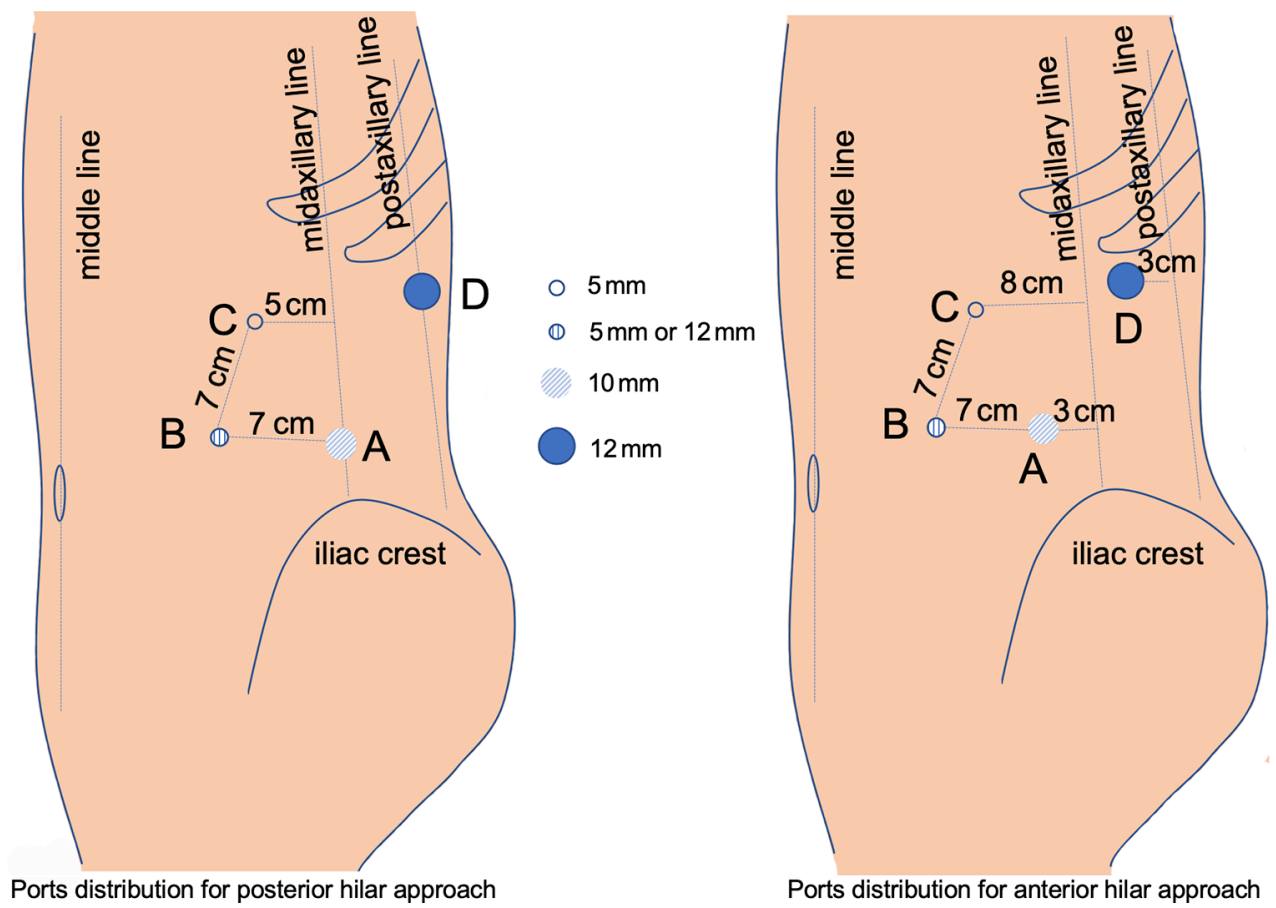

Figure 2 Placement of four ports. The port distribution varies slightly according to the different approaches. Left: port distribution for the posterior hilar approach. Port A is $2 \mathrm{~cm}$ above the iliac crest at the midaxillary line; the distance between ports B and C and between ports $\mathrm{A}$ and $\mathrm{B}$ is approximately $7 \mathrm{~cm}$; port $\mathrm{D}$ is below the twelfth rib at the postaxillary line. Right: port distribution for the anterior hilar approach. The four ports are placed $3 \mathrm{~cm}$ forward to the midline compared with the posterior hilar approach. The distances between ports are unchanged. 


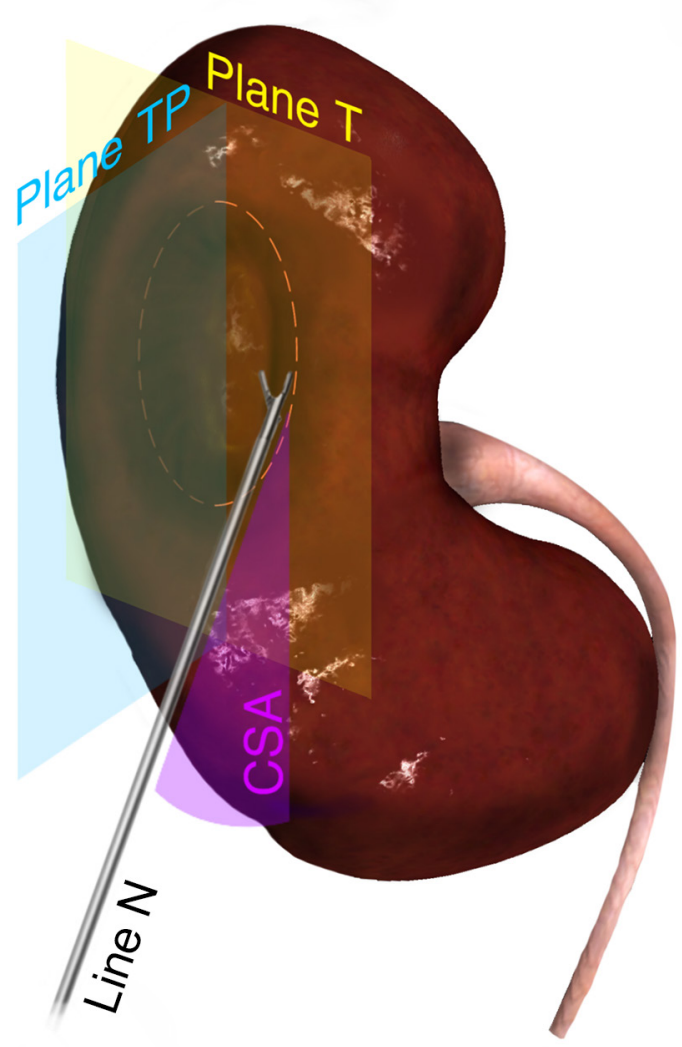

Figure 3 Comfortable suture angle (CSA). The longest vertical and transverse diameter lines on the superficial parenchyma defect forms a tumor plane (Plane T). T perpendicular plane (Plane TP) is perpendicular to Plane $\mathrm{T}$ while passing through the longest vertical diameter line. The needle holder is treated as a reference line (Line $\mathrm{N}$ ). Line $\mathrm{N}$ and Plane $\mathrm{T}$ form a suture angle. CSA was defined as less than 30 degrees.

distribution of these four ports varied according to the surgical approach. For the anterior tumor, the four ports were placed $3 \mathrm{~cm}$ forward to the midline compared with the posterior tumor (9).

For precise segmental artery clamping, we advocated different approaches to dissect target arteries of different tumor types. These approaches were the anterior hilar, posterior hilar, or combined approach. The choice of approach depended on the vasculature model, as our previous work described (9).

\section{Targeted/main artery clamping and tumor excision}

Once the ports were applied, extraperitoneal fat was removed. The Gerota fascia was incised, and perirenal fat was excised to expose the tumor and surrounding parenchyma. Perihilar fat was also removed to facilitate further dissection of target branches. The targeted segmental renal arteries were isolated at the pulsatile position, as well as the main renal artery, in case of unfortuitous events. The targeted segmental renal arteries were clamped with bulldogs before removing the tumor. The tumor was excised from the parenchyma bed by sharp and blunt dissection that was restricted to the outside of the pseudocapsule.

\section{Renorrbaphy and CSA}

Generally, the surgeon stands on the back of the patient. It is convenient for the right-handed surgeon to perform renorrhaphy using the needle holder inserted through the posterior axillary line port for a left kidney tumor. At the same time, assisted forceps was put in through the anterior axillary line port.

Two reference planes and a reference line were visualized (Figure 3) as a guide for the parenchyma defect closure. The longest vertical and transverse diameter lines on the superficial parenchyma defect formed a tumor plane (Plane $\mathrm{T})$. The tumor-perpendicular plane (Plane TP), as the name suggests, is perpendicular to Plane $T$ while passing through the longest vertical diameter line. The needle holder was treated as the reference line (Line $\mathrm{N}$ ). When suturing the defect, Line $\mathrm{N}$ was close and parallel to Plane TP. Line N and Plane $\mathrm{T}$ then forms an angle, the suture angle.

To detect a better suture angle (the CSA), ten volunteer doctors who each had more than 2-year experience performing partial nephrectomy in our center performed a simulated surgery. In simulation, a laparoscopic surgery simulator was applied and a simulated suture model was placed on a platform with an adjustable angle. A 5 -cm defect was closed at different suture angles $\left(15^{\circ}, 30^{\circ}, 45^{\circ}\right.$, $\left.60^{\circ}\right)$, with double-layer and continuous sutures. The suture time and ease of performance was recorded (Table S1). The ideal CSA was defined as the suture angle that required the least suture time with the greatest ease of performance.

We designed an angle measurement aid to detect whether the CSA could be achieved during suturing. This tiny angle-adjustable device consisted of two smooth metal pieces and was fixed to a maximal angle of $30^{\circ}$. Before closing the defect, the needle holder held one piece and the other was opened to measure the suture angle. If the suture angle was bigger than the device's maximal angle, then it was recorded as not achieving the CSA (i.e., non-CSA). 
Table 1 Patient and tumor characteristics

\begin{tabular}{|c|c|}
\hline Characteristics & Value \\
\hline Age, years & $55.31 \pm 12.21$ \\
\hline Body mass index, $\mathrm{kg} / \mathrm{m}^{2}$ & $22.74 \pm 2.05$ \\
\hline \multicolumn{2}{|l|}{ Gender, n (\%) } \\
\hline Male & $68(64.15)$ \\
\hline Female & $38(35.85)$ \\
\hline Tumor size, $\mathrm{cm}$ & $3.42 \pm 1.30$ \\
\hline RNS, median [range] & $6[4-10]$ \\
\hline Preoperative GFR ${ }^{\star}, \mathrm{mL} / \mathrm{min}$ & $45.76 \pm 7.88$ \\
\hline \multicolumn{2}{|l|}{ T stage, n (\%) } \\
\hline T1a & $82(77.36)$ \\
\hline $\mathrm{T} 1 \mathrm{~b}$ & $24(22.64)$ \\
\hline \multicolumn{2}{|l|}{ Tumor location, n (\%) } \\
\hline Anterior & $32(30.19)$ \\
\hline Lower polar & $28(26.42)$ \\
\hline Posterior & $24(22.64)$ \\
\hline Upper polar & $22(20.75)$ \\
\hline \multicolumn{2}{|l|}{ Growth pattern, n (\%) } \\
\hline Exophytic & $50(47.17)$ \\
\hline Mesophytic & $29(27.36)$ \\
\hline Endophytic & $27(25.47)$ \\
\hline \multicolumn{2}{|l|}{ Pathology, n (\%) } \\
\hline Clear cell carcinoma & 77 (72.64) \\
\hline Angiomyolipoma & $15(14.15)$ \\
\hline Papillary carcinoma & $6(5.66)$ \\
\hline Oncocytoma & $5(4.72)$ \\
\hline Chromophobe cell carcinoma & $3(2.83)$ \\
\hline
\end{tabular}

*, affected side.

Otherwise, it was recorded as achieving the CSA.

\section{Clinical data}

The patients' demographic, age, gender, and body mass index data were collected. The clinicopathologic characteristics of the tumor were noted, including: size; location (anterior, posterior, upper polar, lower polar); growth pattern (exophytic, mesophytic, endophytic); number of targeted renal arteries feeding the tumor; and
R.E.N.A.L. nephrometry score (RNS). In addition, the following features were carefully collected: perioperative data such operative and clamping time, estimated blood loss, pathology, and positive surgical margin; postoperative glomerular filtration rate (GFR); and complications. Two radiologists were blinded to the RNSs, in accordance with Kutikov and Uzzo (13). Complications were graded based on Clavien's classification (14). For analysis, patients were classified as CSA or non-CSA, depending on whether the CSA was achieved.

\section{Statistical analysis}

All the data were analyzed by STATA 14.0 software. Perioperative characteristics of different tumor types were compared using the $t$-test, chi-squared test, or one-way analysis of variance. Univariable and multivariable logistic regression analyses were utilized to investigate associations between patient or tumor characteristics and successfully getting a CSA. $\mathrm{P}<0.05$ was considered statistically significant.

\section{Results}

\section{Patient and tumor characteristics}

The 106 patients consisted of 68 men $(64.15 \%)$ and 38 women $(35.85 \%)$. The patients' mean age was 55.31 years and body mass index was $22.74 \mathrm{~kg} / \mathrm{m}^{2}$. Regarding the tumor characteristics, the mean tumor diameter was $3.42 \mathrm{~cm}$, with $77.36 \%$ and $22.64 \%$ in $\mathrm{T} 1 \mathrm{a}$ and $\mathrm{T} 1 \mathrm{~b}$ stage, respectively. The median RNS was 6 (range, 4-10).

The majority of the tumors $(72.64 \%)$ were clear cell carcinoma, with angiomyolipoma $(14.15 \%)$, papillary carcinoma (5.66\%), oncocytoma (4.72\%), and chromophobe cell carcinoma (2.83\%) making up the balance (Table 1).

\section{Overall perioperative outcomes}

Of the 106 patients, 96 (90.57\%) underwent segmental renal artery clamping and the remaining $(9.43 \%)$ received main renal artery clamping upon failure to clamp segmental renal arteries (Table 2). No patient received radical nephrectomy or open surgery. The mean operative time was 78 minutes and the mean suture time was 13 minutes. The warm ischemic time was 19 minutes. The estimated blood loss was $117 \mathrm{~mL}$. The total complication rate was $16.98 \%$. Ten patients were found postoperatively with hematuria 
Table 2 Perioperative and functional outcomes in patients with CSA and non-CSA

\begin{tabular}{|c|c|c|c|c|}
\hline Variables & Overall $(n=106)$ & $\operatorname{CSA}(n=89)$ & Non-CSA $(n=17)$ & $\mathrm{P}^{\mathrm{a}}$ \\
\hline Clamping time, $\min$ & $18.92 \pm 5.47$ & $18.18 \pm 4.85$ & $22.82 \pm 6.91$ & 0.001 \\
\hline Suture time, $\min$ & $12.92 \pm 4.94$ & $12.34 \pm 4.65$ & $15.94 \pm 5.43$ & 0.005 \\
\hline Estimated blood loss, $\mathrm{mL}$ & $116.79 \pm 82.61$ & $109.33 \pm 84.02$ & $155.88 \pm 63.45$ & 0.005 \\
\hline GFR reduction ${ }^{\mathrm{b}}, \%$ & $31.77 \pm 11.09$ & $31.21 \pm 11.23$ & $34.67 \pm 10.11$ & 0.240 \\
\hline Complication rate, $\mathrm{n}(\%)^{\mathrm{c}}$ & $18(16.98)$ & $13(14.6)$ & $5(29.4)$ & 0.097 \\
\hline 1 & 10 & 8 & 2 & - \\
\hline
\end{tabular}

${ }^{a}$, P value was calculated between CSA and non-CSA groups; ${ }^{b}$, affected side; ${ }^{c}$, complication grades: 1 , hematuria; 2 , major hemorrhage requiring transfusion; 3a, postoperative hemorrhage requiring intervention. CSA, comfortable suture angle; GFR, glomerular filtration rate.

(grade 1), with no intervention taken. Seven patients required blood transfusion due to major hemorrhage (grade 2). One patient received branch embolization one day after surgery, because of postoperative hemorrhage (grade 3a).

\section{Determination of CSA}

Compared with $45^{\circ}$ and $60^{\circ}$, angles of $15^{\circ}$ or $30^{\circ}$ required less suture time and were more comfortable to achieve by the surgeon, based on the surgical simulations $(\mathrm{P}<0.001)$. The angles $15^{\circ}$ and $30^{\circ}$ were comparable by these measures. Therefore, we defined CSA as a suture angle $<30$ degree.

\section{Perioperative and functional outcomes of patients in the CSA and non-CSA groups}

Of the study population of 106 patients, the CSA was successfully achieved in $89(83.96 \%)$ and the parenchyma recovered (CSA group); in the remaining 17 patients the CSA was not reached, but all were successfully sutured (non-CSA group). Compared with the non-CSA group, the CSA group experienced significantly shorter operative, clamping, and suture times $(\mathrm{P}=0.003,0.001$, and 0.005 , respectively); and lower estimated blood loss $(\mathrm{P}=0.005$; Table 2). However, the two groups were comparable with regard to positive surgical margin $(\mathrm{P}=1.000)$, GFR reduction $(\mathrm{P}=0.240)$, and complication rates $(\mathrm{P}=0.097)$.

\section{Perioperative and functional outcomes in different tumor types}

According to the tumor location, tumors were defined as anterior, posterior, upper polar, or lower polar. Among the tumor types, no differences were found in tumor size $(\mathrm{P}=0.900)$, operative time $(\mathrm{P}=0.899)$, estimated blood loss $(\mathrm{P}=0.901)$, preoperative GFR $(\mathrm{P}=0.112)$, GFR reduction $(\mathrm{P}=0.525)$, or complication rates $(\mathrm{P}=0.295)$. However, there were significant differences in clamping time $(\mathrm{P}=0.026)$, suture time $(\mathrm{P}=0.040)$, and rates of achieving the CSA $(\mathrm{P}=0.011$; Table 3). In particular, the upper and lower polar tumors required more operative and suture time, with lower rates of achieving the CSA, compared with the anterior or posterior tumors.

\section{Associations between patient/tumor features and successful CSA performing}

Univariable and multivariable logistic regression analyses were performed to determine the patient and tumor characteristics that may influence the successful performance of CSA (Table 4). In the univariable analyses, the independent factors affecting the feasibility to perform CSA were RNS $(\mathrm{P}=0.000)$, tumor location (lower polar $c f$. anterior, $\mathrm{P}=0.022$; upper polar $c f$. anterior, $\mathrm{P}=0.029$ ), and growth pattern (mesophytic $c f$. exophytic, $\mathrm{P}=0.006$; endophytic $c f$. exophytic, $\mathrm{P}=0.007)$. The multivariable analyses showed that RNS $(\mathrm{P}=0.018)$ and tumor location 
Table 3 Perioperative and functional outcomes at four tumor locations

\begin{tabular}{|c|c|c|c|c|c|}
\hline Characteristics & \multicolumn{4}{|c|}{ Location } & $P$ \\
\hline Tumor size, cm & $3.28 \pm 1.14$ & $3.45 \pm 1.16$ & $3.50 \pm 1.49$ & $3.50 \pm 1.51$ & 0.900 \\
\hline Operation time, min & $86.72 \pm 13.30$ & $89.11 \pm 13.41$ & $86.46 \pm 16.84$ & $87.73 \pm 13.52$ & 0.899 \\
\hline Clamping time, $\min$ & $23.97 \pm 4.15$ & $27.61 \pm 6.96$ & $25.13 \pm 4.49$ & $27.50 \pm 5.16$ & 0.026 \\
\hline $\mathrm{EBL}, \mathrm{mL}$ & $111.88 \pm 86.49$ & $126.79 \pm 93.77$ & $112.50 \pm 69.55$ & $115.91 \pm 79.26$ & 0.901 \\
\hline Preoperative GFR, mL/min & $43.81 \pm 7.24$ & $44.54 \pm 8.28$ & $48.21 \pm 8.47$ & $47.44 \pm 7.01$ & 0.112 \\
\hline GFR reduction, $\%$ & $30.41 \pm 11.16$ & $32.62 \pm 12.77$ & $30.25 \pm 11.51$ & $34.33 \pm 7.92$ & 0.525 \\
\hline Complication rate, $\mathrm{n}(\%)$ & $5(15.63)$ & $8(28.57)$ & $2(8.33)$ & $3(13.64)$ & 0.295 \\
\hline
\end{tabular}

EBL, estimated blood loss; CSA, comfortable suture angle; GFR, glomerular filtration rate.

Table 4 Factors influencing the successful achievement of the CSA

\begin{tabular}{|c|c|c|c|c|c|c|}
\hline Factors & \multicolumn{3}{|c|}{ Univariable } & \multicolumn{3}{|c|}{ Multivariable } \\
\hline Age & $1.002(0.960-1.046)$ & 0.09 & 0.926 & $1.024(0.960-1.091)$ & 0.71 & 0.475 \\
\hline Gender & $0.971(0.328-2.875)$ & -0.05 & 0.958 & $0.936(0.228-3.850)$ & -0.09 & 0.927 \\
\hline Body mass index & $1.093(0.833-1.433)$ & 0.64 & 0.522 & $1.143(0.814-1.606)$ & 0.77 & 0.441 \\
\hline Tumor size & $0.777(0.529-1.142)$ & -1.28 & 0.200 & $0.878(0.516-1.496)$ & -0.48 & 0.633 \\
\hline RNS & $0.467(0.305-0.714)$ & -3.51 & 0.000 & $0.488(0.003-0.885)$ & -2.36 & 0.018 \\
\hline \multicolumn{7}{|l|}{ Tumor location } \\
\hline Anterior & - & - & - & - & - & - \\
\hline Upper polar & $0.086(0.010-0.777)$ & -2.18 & 0.029 & $0.036(0.002-0.548)$ & -2.39 & 0.017 \\
\hline \multicolumn{7}{|c|}{ Tumor growth pattern } \\
\hline Exophytic & - & - & - & - & - & - \\
\hline Mesophytic & $0.053(0.006-0.456)$ & -2.68 & 0.006 & $0.173(0.017-1.810)$ & -1.46 & 0.143 \\
\hline Endophytic & $0.048(0.006-0.414)$ & -2.77 & 0.007 & $0.093(0.007-1.126)$ & -1.87 & 0.062 \\
\hline
\end{tabular}

CSA, comfortable suture angle; GFR, glomerular filtration rate; OR, odds ratio; $\mathrm{Cl}$, confidence interval. 
(lower polar $c f$. anterior, $\mathrm{P}=0.046$; upper polar $c f$. anterior, $\mathrm{P}=0.017)$ were the factors that may influence the successful performance of CSA.

\section{Discussion}

Suturing has been one of the top challenges since the emergence of laparoscopic surgery. Recently, improvements in suture skills and application of barbed sutures make it easier to performed renorrhaphy during LPN. However, with the retroperitoneal approach, suturing is often limited by the space and the instruments, making relatively difficult to handle. Trocar position is considered as one of the most important factors affecting suture procedure. It may influence the angle of vision and operating (15). Optimized trocar position was then conducted to modify and ease the suturing. Previous studies have reported a series of innovations in suture technology, but they only focused on suture skills, and some are even more complicated to perform. In this article, we introduced the new concept of CSA, with which we can effectively suture different tumor types.

The CSA was proposed based on our longtime experience and preliminary experimentations. We preferred to perform renorrhaphy along the tumor long axis, in case of high suture tension and possible parenchyma laceration. Thus, we introduced the Plane TP, perpendicular to the tumor plane (Plane T), as a reference that can be used to position the needle holder parallel to it and aid suturing of the defect. However, even if we did so, we sometimes could still experience a very awkward renorrhaphy. We then determined upon a suture angle that consisted of both the tumor plane (Plane T) and the needle holder (Line $\mathrm{N}$ ) as important factors. The more the needle holder was parallel to the tumor plane, the easier the suture was to perform. Yet, such a perfect angle could not be achieved in every case. Thus, the concept of the CSA came into being, and was defined as an angle ranging from 0 to 30 degrees.

The CSA simplifies complex surgical procedures and approaches with a flexible suture angle that can accommodate any safe position change. In addition, it is relatively easy to understand by junior learners and reduces the learning curve. The present study also determined that the CSA is feasible and safe to achieve. The CSA was implemented in most of the surgical patients $(83.96 \%)$ through kidney position change.

Successfully using the CSA was shown to significantly shorten the operative, clamping, and suture times, making closing the parenchyma defect easier during the partial nephrectomy ( $\mathrm{P}=0.003,0.001,0.005$, respectively), and there was significantly less estimated blood loss $(\mathrm{P}=0.005)$. This suggests that using the CSA lowered the risk of bleeding.

At the same time, the CSA and non-CSA groups were comparable with regard to positive surgical margin, GFR reduction, and complication rates $(\mathrm{P}=1.000,0.240$, and 0.097 , respectively). Warm ischemic time for 25 to 30 minutes has been associated with the loss of renal function $(16,17)$. In both our groups, the clamping time was less than 25 minutes, and the GFR reduction was similar. Of note, while the complication rates of the two groups were statistically similar, that of the non-CSA group was higher.

During partial nephrectomy, the tumor location is a main factor affecting the suture and surgical procedures. Thus, in this study the perioperative outcomes of four tumor types were compared when trying to achieve the CSA. Among the four types, tumor size $(\mathrm{P}=0.900)$ and preoperative GFR $(\mathrm{P}=0.112)$ were similar, which indicated a comparable foundation. However, there were significant differences in the rates of achieving the CSA $(\mathrm{P}=0.011)$. Specifically, the rates were highest for anterior $(96.88 \%)$ and posterior (91.67\%) tumors, while achieving the CSA was more difficult for upper polar (72.73\%) and lower polar (71.43\%). Clamping and suture for upper and lower polar tumors took more time, indicating a higher difficulty in suturing. Yet, the operative times of the 4 tumor types were similar $(\mathrm{P}=0.899)$. This is reasonable, when considering that operative time is not only affected by the time to remove the tumor and close the defect, but many other factors such as perirenal adhesion as our previous work showed (18). The tumor types were of no importance to the safety of the CSA, as both groups were similar with regard to estimated blood loss $(\mathrm{P}=0.901)$, GFR reduction $(\mathrm{P}=0.525)$, or complication rates $(\mathrm{P}=0.295)$.

We further detected factors that may influence the successful achievement of the CSA. The univariable analyses indicated that the independent factors affecting the feasibility to perform CSA were RNS $(\mathrm{P}=0.000)$, tumor location (lower polar $c f$. anterior, $\mathrm{P}=0.022$; upper polar $c f$. anterior, $\mathrm{P}=0.029$ ), and growth pattern (mesophytic $c f$. exophytic, $\mathrm{P}=0.006$; endophytic $c f$. exophytic, $\mathrm{P}=0.007$ ). However, the multivariable analyses showed that only tumor location (lower polar $c f$. anterior, $\mathrm{P}=0.046$; upper polar $c f$. anterior, $\mathrm{P}=0.017)$ and $\mathrm{RNS}(\mathrm{P}=0.018)$ were independent factors that may influence the successful performance of CSA. RNS is a scoring system for anatomical features of 
solid renal masses, and putatively can predict the difficulty of surgery (18); a higher RNS indicates a more complicated mass. In the present study, there was an inverse association between RNS and the rate of achieving the CSA.

The RNS incorporates many aspects of the tumor, including radius, exophytic or endophytic properties, nearness to the sinus, anterior/posterior, and location relative to the polar lines. In the present study, the radius (reflecting size) and exophytic/endophytic properties did not affect the rate of CSA success, but factors related to tumor location (nearness to the sinus, anterior/posterior, and relationship to the polar lines) did correlate.

Anterior and posterior tumors are usually easy to isolate and the parenchyma defect often has more space to move. Through proper position change it was easy to get the CSA. Because the anterior tumor showed the highest rate, it was taken as the reference. The ability to use the CSA was more likely for lower polar tumors $(\mathrm{P}=0.046)$ and the upper polar tumors $(\mathrm{P}=0.017)$, but posterior tumors $(\mathrm{P}=0.228)$ showed no correlation to rate of success.

Polar tumors were usually considered not so easy to handle. Attempts to modify port upward and downward got little effect on CSA achieving rate for polar tumors. More factors should take into account so that to get better CSA rate. Lower polar tumors are usually thought difficult to suture and our data supported this; the tumor defect is always downward. Through proper position fixing, we can make Plane TP parallel to Line N. However, it is not easy to make a suture angle less than 30 degrees. Elevation of the lower pole with forceps or gauze makes it more feasible to close the defect. An upper polar tumor is considered easier to handle, but showed low CSA achievement rates. We then carefully reviewed our data and found that in all six cases in which the attempt to achieve the CSA failed, the tumor was on the medial side of the upper pole. Most other upper polar tumors were indeed easier to manage, but the mobility of upper polar tumors on the medial side is limited by the hilar structure. What is more, the defect in this part was often facing head and inside. Thus, Plane $\mathrm{T}$ and Line $\mathrm{N}$ were not easy to align to get the CSA. The entire kidney should be free and lay down to the dorsal. The defect needs to be turned towards the surgeon as much as possible to make the suture more comfortable.

Though the feasibility and safety of CSA have been confirmed in this study, there are still some limitations. While performing the analysis, there were only a small number of some tumor types, which may affect the accuracy of the results, and more cases need to be included for confirmation.

Factors that affect suturing are complex. The CSA concept, developed through surgical experience, makes understanding these procedures easier. Application of the CSA is a useful adjunct to advances in suture techniques and methods, including robot-assisted technology. We're also conducting pre-operative imaging and software aiming to help surgeons better place the trocars and get the CSA which may be more interesting and helpful.

\section{Conclusions}

In this study, the position change implemented with the CSA and modified trocar position was shown to be feasible, useful, and safe, and makes the suture process during retroperitoneal LPN easier. Successful use of the CSA approach is particularly influenced by tumor location and RNS.

\section{Acknowledgments}

Funding: This study was supported by Key Research and Development of Jiangsu Province (BE2018749) and National Natural Science Foundation of China (grant No. 82002697).

\section{Footnote}

Reporting Checklist: The authors have completed the MDAR reporting checklist. Available at http://dx.doi.org/10.21037/ tau-20-1126

Data Sharing Statement: Available at http://dx.doi. org/10.21037/tau-20-1126

Peer Review File: Available at http://dx.doi.org/10.21037/ tau-20-1126

Conflicts of Interest: All authors have completed the ICMJE uniform disclosure form (available at http://dx.doi. org/10.21037/tau-20-1126). The authors have no conflicts of interest to declare.

Ethical Statement: The authors are accountable for all aspects of the work in ensuring that questions related to the accuracy or integrity of any part of the work are appropriately investigated and resolved. The study was conducted in accordance with the Declaration of Helsinki 
(as revised in 2013). The study was approved by the Local Ethics Committees of First Affiliated Hospital with Nanjing Medical University (No.:2016-SRFA-009) and informed consent was taken from all the patients.

Open Access Statement: This is an Open Access article distributed in accordance with the Creative Commons Attribution-NonCommercial-NoDerivs 4.0 International License (CC BY-NC-ND 4.0), which permits the noncommercial replication and distribution of the article with the strict proviso that no changes or edits are made and the original work is properly cited (including links to both the formal publication through the relevant DOI and the license). See: https://creativecommons.org/licenses/by-nc-nd/4.0/.

\section{References}

1. Campbell S, Uzzo RG, Allaf ME, et al. Renal Mass and Localized Renal Cancer: AUA Guideline. J Urol 2017;198:520-9.

2. Hung AJ, Cai J, Simmons MN, et al. "Trifecta" in partial nephrectomy. J Urol 2013;189:36-42.

3. Porpiglia F, Bertolo R, Amparore D, et al. Nephronsparing Suture of Renal Parenchyma After Partial Nephrectomy: Which Technique to Go For? Some Best Practices. Eur Urol Focus 2019;5:600-3.

4. Benway BM, Wang AJ, Cabello JM, et al. Robotic partial nephrectomy with sliding-clip renorrhaphy: technique and outcomes. Eur Urol 2009;55:592-9.

5. Gill IS, Desai MM, Kaouk JH, et al. Laparoscopic partial nephrectomy for renal tumor: duplicating open surgical techniques. J Urol 2002;167:469-7; discussion 475-6.

6. Hillyer S, Spana G, White MA, et al. Novel robotic renorrhaphy technique for hilar tumours: 'V' hilar suture (VHS). BJU Int 2012;109:1572-7.

7. Zhang C, Li X, Yu W, et al. Ring Suture Technique in Retroperitoneal Laparoscopic Partial Nephrectomy for Hilar Cancer: A New Renorrhaphy Technique. J Endourol 2016;30:390-4.

Cite this article as: Qian J, Zhang Q, Cao Q, Jiang J, Li P, Bao M, Qin C, Wang Z, Hua L, Shao P. Comfortable suture angle with optimized trocar position aids renorrhaphy during retroperitoneal laparoscopic partial nephrectomy. Transl Androl Urol 2021;10(3):1030-1039. doi: 10.21037/tau-20-1126
8. Shao P, Tang L, Li P, et al. Precise segmental renal artery clamping under the guidance of dual-source computed tomography angiography during laparoscopic partial nephrectomy. Eur Urol 2012;62:1001-8.

9. Shao P, Tang L, Li P, et al. Application of a vasculature model and standardization of the renal hilar approach in laparoscopic partial nephrectomy for precise segmental artery clamping. Eur Urol 2013;63:1072-81.

10. Didio LJA. Segments of the kidney: the anatomical basis for nephrosegmentectomy. Developments in Nephrology 1985;5:1-12.

11. Anderson JK, Kabalin JN, Cadeddu JA. Surgical anatomy of the retroperitoneum, adrenals, kidneys and ureters. In: Campbell-Walsh Urology. 9th edition. Philadelphia: Saunders Elsevier, 2007:3-37.

12. Finley DS, Lee DI, Eichel L, et al. Fibrin glue-oxidized cellulose sandwich for laparoscopic wedge resection of small renal lesions. J Urol 2005;173:1477-81.

13. Kutikov A, Uzzo RG. The R.E.N.A.L. nephrometry score: a comprehensive standardized system for quantitating renal tumor size, location and depth. J Urol 2009;182:844-53.

14. Dindo D, Demartines N, Clavien PA. Classification of surgical complications: a new proposal with evaluation in a cohort of 6336 patients and results of a survey. Ann Surg 2004;240:205-13.

15. Ames C, Frisella AJ, Yan Y, et al. Evaluation of laparoscopic performance with alteration in angle of vision. J Endourol 2006;20:281-3.

16. Volpe A, Blute ML, Ficarra V, et al. Renal Ischemia and Function After Partial Nephrectomy: A Collaborative Review of the Literature. Eur Urol 2015;68:61-74.

17. Rod X, Peyronnet B, Seisen T, et al. Impact of ischaemia time on renal function after partial nephrectomy: a systematic review. BJU Int 2016;118:692-705.

18. Qian J, Jiang J, Li P, et al. Factors Influencing the Feasibility of Segmental Artery Clamping During Retroperitoneal Laparoscopic Partial Nephrectomy. Urology 2019;129:92-7. 
Supplementary

Table S1 Suture time and comfort value in different suture angles

\begin{tabular}{lccccc}
\hline & $15^{\circ}$ & $30^{\circ}$ & $45^{\circ}$ & $60^{\circ}$ & $P$ \\
\hline Suture time, $\min$ & $4.49 \pm 0.64$ & $4.57 \pm 0.76$ & $5.82 \pm 1.31$ & $6.88 \pm 1.39$ & 0.000 \\
Comfort value & $9.30 \pm 0.82$ & $9.20 \pm 0.79$ & $6.50 \pm 0.85$ & $4.80 \pm 0.63$ & 0.000 \\
\hline
\end{tabular}

